\title{
Thermal disorder and correlation effects in anti-perovskite-type copper nitride
}

\author{
Janis Timoshenko ${ }^{\mathrm{a}, \mathrm{b}, *}$, Andris Anspoks $^{\mathrm{b}}$, Alexandr Kalinko $^{\mathrm{c}}$, Alexei Kuzmin $^{\mathrm{b}}$ \\ ${ }^{a}$ Department of Materials Science and Chemical Engineering, Stony Brook University, NY 11794, USA \\ ${ }^{b}$ Institute of Solid State Physics, University of Latvia, Kengaraga street 8, LV-1063 Riga, Latvia \\ ${ }^{c}$ Universität Paderborn, Naturwissenschaftliche Fakultät, Department Chemie, Warburger Straße 100, 33098 Paderborn, Germany
}

\begin{abstract}
Reverse Monte Carlo simulations coupled with evolutionary algorithm were employed for the analysis of the temperature dependent (10-300 K) Cu K-edge extended X-ray absorption fine structure (EXAFS) spectra of polycrystalline copper nitride $\left(\mathrm{Cu}_{3} \mathrm{~N}\right)$ with the goal to extract information on the thermal disorder and interatomic correlations in antiperovskite-type crystal lattice. The obtained results are discussed in comparison with metallic copper and perovskite-type rhenium trioxide. The analysis of EXAFS spectra suggests that the anisotropy of copper atom vibrations is significantly enhanced upon increasing temperature, leading to pronounced tilting motion of $\mathrm{NCu}_{6}$ octahedra. Strong correlation in the motion of atoms was found along $-\mathrm{N}-\mathrm{Cu}-\mathrm{N}-$ atomic chains but it reduces rapidly with an increase of interatomic distance. Finally, anticorrelated motion of neighboring $\mathrm{Cu}$ atoms occurs along $\mathrm{Cu}-\mathrm{Cu}$ bonds and is consistent with breathing-type motion of $\mathrm{NCu}_{6}$ octahedra.
\end{abstract}

Keywords: $\mathrm{Cu}_{3} \mathrm{~N}$, EXAFS, Reverse Monte Carlo simulations, Lattice dynamics

\section{Introduction}

Materials with perovskite-type structure are appealing due to their relatively simple and stable structure, numerous possible technological applications and a broad range of properties, which can be tuned, e.g., by substituting cations at the sites $\mathrm{A}$ and $\mathrm{B}$ of $\mathrm{ABX}_{3}$ perovskite crystal lattice $[1,2,3,4,5,6]$. Many of the unique properties of perovskite-type materials are a result of local distortions and peculiar atomic dynamics in such materials. Importance of such effects as anisotropy and anharmonicity of atomic vibrations and the presence of strong correlations in atomic displacements is acknowledged, for instance, in many studies of phase-transitions $[7,8,9]$, ferroelectric properties $[7,10,11]$ and negative thermal expansion effect $[12,13,14,15]$, observed in perovskites.

So-called anti-perovskite materials have similar to perovskites crystal structure, which can be described by the same formula $\mathrm{ABX}_{3}$, but now the $\mathrm{X}$ site is occupied by a metal cation, while $\mathrm{B}$ site is occupied by light anion. While less studied than perovskites, anti-perovskite-type materials also exhibit a number of intriguing properties, such as giant negative thermal expansion, observed in Gedoped $\mathrm{MnN}$ [16], superconductivity, observed in $\mathrm{MgCNi}_{3}$ [17], and giant magnetoresistance, detected for $\mathrm{Mn}_{3} \mathrm{GaC}$ [18]. One can expect that the local structure and dynamics play as important role for the understanding of properties of anti-perovskites as they do in the case of perovskites.

\footnotetext{
*Corresponding author

Email address: janis.timoshenko@gmail.com (Janis Timoshenko)
}

Nevertheless, the dynamical properties and interatomic correlations in anti-perovskites have been investigated to much less extent.

Therefore in this study we apply a novel approach, which combines possibilities, provided by X-ray absorption spectroscopy and advanced simulation-based analysis, to investigate the local structure and dynamics of copper nitride $\mathrm{Cu}_{3} \mathrm{~N}$, a narrow band gap $(0.25-1.90 \mathrm{eV}$ [19]) semiconductor with a cubic anti-perovskite-type structure. Particular attention is paid to the analysis of interatomic correlations and their dependence on temperature.

Copper nitride consists of regular, corner-shared $\mathrm{NCu}_{6}$ octahedra [20, 21] (see the inset in Fig. 1), and is a metastable material. $\mathrm{Cu}_{3} \mathrm{~N}$ thin films can be easily produced by magnetron sputtering, and their crystallinity can be controlled by substrate temperature [22]. Upon temperature increase above $100^{\circ} \mathrm{C}$ nitrogen is released from thin film $\mathrm{Cu}_{3} \mathrm{~N}$, and the material turns into metallic copper. Hence the use of copper nitride in write-once memory devices $[23,24,25,26$, 27], as a seed layer for electrodeposition [28] and in optical lithography for fabrication of metal links $[29,30]$ was proposed. At the same time, bulk material is stable at room temperature, but decomposes at $300-450^{\circ} \mathrm{C}$. Other possible applications of $\mathrm{Cu}_{3} \mathrm{~N}$ are related to spintronics [31,32], electrocatalysis [33], solar energy conversion [19, 34], resistive switching memories $[35,36]$ and inorganic-organic electronics [37].

The equilibrium structure of $\mathrm{Cu}_{3} \mathrm{~N}$ is known from $\mathrm{X}$ ray [20] and neutron [21] diffraction. The results obtained by both methods show also a significant anisotropy of copper thermal motion, which increases upon temperature in- 

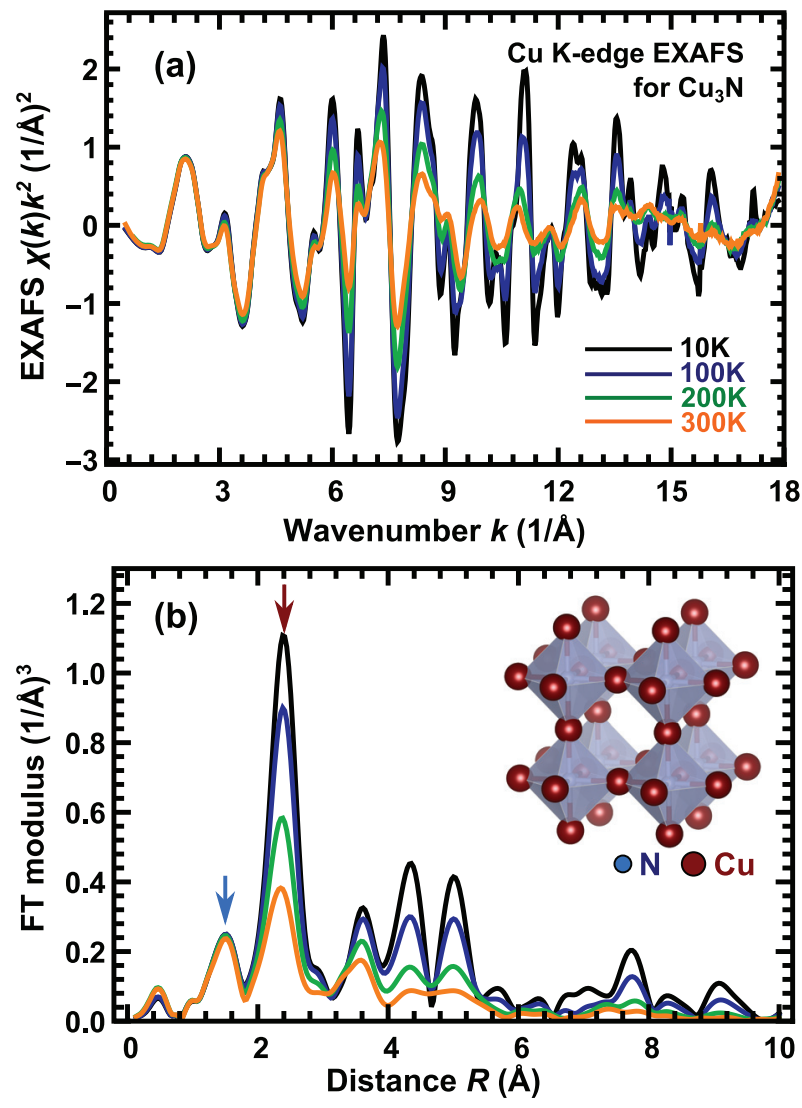

Figure 1: (Color online) The experimental Cu K-edge EXAFS spectra (a) and their Fourier transforms (FTs) (b) at four selected temperatures. The first peak at $1.3 \AA$ corresponds to two nearest nitrogen atoms of the first coordination shell of copper, whereas the second peak at $2.4 \AA$ corresponds to eight copper atoms forming the second coordination shell. The inset in (b) shows the crystal structure of cubic $\mathrm{Cu}_{3} \mathrm{~N}$ composed of $\mathrm{NCu}_{6}$ octahedra [20, 21].

crease [20]. In this sense the behaviour of $\mathrm{Cu}_{3} \mathrm{~N}$ is similar to the one, observed for such perovskite-type materials as rhenium oxide $\mathrm{ReO}_{3}$ and scandium fluoride $\mathrm{ScF}_{3}$ $[14,15,38]$. The character of chemical bonding in $\mathrm{Cu}_{3} \mathrm{~N}$, in turn, has been a subject of the discussion in the literature. In particular, theoretical studies suggest covalent bonding of $\mathrm{Cu}$ and $\mathrm{N}$ atoms rather than simple ionic interaction between $\mathrm{Cu}^{1+}$ and $\mathrm{N}^{3-}$ ions [39]. At the same time, it was proposed in [40] that metallic-type bonding may also contribute to the properties of $\mathrm{Cu}_{3} \mathrm{~N}$, especially at elevated pressures. Note that copper-copper distances in $\mathrm{Cu}_{3} \mathrm{~N}$ are just slightly larger than those in close-packed metallic copper $[41,42]$. Together with the fact that $\mathrm{Cu}_{3} \mathrm{~N}$ is easily transforming into metallic copper upon temperature increase, this observation may allow to speculate that interatomic interactions in $\mathrm{Cu}_{3} \mathrm{~N}$ may resemble those in copper. Experimental evidences on the character of such interactions, however, currently are absent.

To investigate this issue, we employ advanced analysis of the $\mathrm{Cu}$ K-edge extended X-ray absorption fine structure (EXAFS). EXAFS spectroscopy is a well-established experimental technique to study the distributions of in- teratomic distances within the nearest coordination shells around absorbing atom. During the last decades it was widely used to study the local structure and dynamics in a broad range of materials $[43,44,45]$. The possibilities to use EXAFS data to probe interatomic correlations, in turn, are much less exploited, despite the fact that sensitivity of EXAFS to these effects is acknowledged [45, 46, 47].

We have demonstrated recently $[48,49]$ that it is feasible to obtain the information on interatomic correlations, if EXAFS analysis is coupled with theoretical simulations and such advanced approaches as reverse Monte Carlo (RMC) [50] and evolutionary algorithm (EA) [48] methods. The combined RMC/EA-EXAFS approach was successfully applied to studies of such perovskite-type materials as $\mathrm{ReO}_{3}, \mathrm{H}_{x} \mathrm{ReO}_{3}[48,49,51,52], \mathrm{SrTiO}_{3}$ [53] and $\mathrm{FeF}_{3}[54]$.

In this study we apply RMC/EA-EXAFS method to extract information on interatomic distances and amplitudes of absolute and relative atomic motion within the first seven coordination shells around $\mathrm{Cu}$ atoms in $\mathrm{Cu}_{3} \mathrm{~N}$. Note that the validation of RMC/EA-EXAFS approach for $\mathrm{Cu}_{3} \mathrm{~N}$ was presented in [55]. Here we analyze temperature dependent changes in the structural parameters upon temperature increase from $10 \mathrm{~K}$ to $300 \mathrm{~K}$. The central result of this paper is the analysis of correlations in the motion of nearest $\mathrm{Cu}-\mathrm{N}$ and $\mathrm{Cu}-\mathrm{Cu}$ neighbors. We show that despite the fact that the crystallographic structure or $\mathrm{ReO}_{3}$ and $\mathrm{Cu}_{3} \mathrm{~N}$ are the same, correlation properties are very different in these two materials.

\section{Experimental details}

Temperature-dependent $\mathrm{Cu}$ K-edge (8979 eV) X-ray absorption spectra of $\mathrm{Cu}_{3} \mathrm{~N}$ were acquired in transmission mode at the bending magnet beamline $\mathrm{C}$ [56] at HASYLAB/DESY synchrotron radiation facility. For this experiment we used commercially available polycrystalline $\mathrm{Cu}_{3} \mathrm{~N}$ powder (99.5\% purity), purchased from Alfa Aesar. The powder was characterized by X-ray diffraction to confirm its phase purity.

To achieve the best homogeneity of the sample for XAS measurements, polycrystalline $\mathrm{Cu}_{3} \mathrm{~N}$ powder was deposited on Millipore filter, and then fixed by Scotch tape. The sample thickness $x$ was optimized to obtain the jump in X-ray absorption coefficient at the $\mathrm{Cu}$ K-edge equal to $\Delta \mu_{x} \approx 1$.

During the XAS measurements, the storage ring DORIS III operated at the energy $E=4.44 \mathrm{GeV}$ and with the current $I_{\max }=140 \mathrm{~mA}$. Double crystal Si(111) monochromator was used for energy selection. To remove the higher order harmonics, the crystals were detuned by $60 \%$. For this purpose the beam-stabilization feedback control was employed. The intensity of X-ray beam before and after the sample was measured using ionization chambers, filled with argon and krypton gases. Copper foil was used as a reference material for energy calibration. Its room temperature $\mathrm{Cu}$ K-edge X-ray absorption spectrum was simul- 
taneously acquired and used later for data alignment. The temperature of the sample was controlled in the range from $10 \mathrm{~K}$ to $300 \mathrm{~K}$ using helium-flow cryostat.

The experimental $\mathrm{Cu}$ K-edge EXAFS spectra $\chi(k) k^{2}$, acquired at different temperatures, were extracted, aligned and processed using conventional procedure $[57,58]$. They are shown together with their Fourier transforms (FTs) in Fig. 1.

Low temperature $\mathrm{Cu}$ K-edge X-ray absorption spectra of copper foil at $T=10$ and $150 \mathrm{~K}$, which were used for comparison, were taken from [59].

\section{Reverse Monte Carlo simulations}

In the RMC-EXAFS method a 3D model of material structure is obtained in an iterative process, involving random displacements of atoms in the presence of proper geometrical constraints with the aim to minimize the difference between the experimental and calculated EXAFS spectra $[51,60]$. Once the structural model is available, the structural parameters of interest, including correlations, can be calculated directly via simple statistical analysis of atomic coordinates. Hence RMC approach is a natural way to investigate correlations in atomic vibrations, providing that the used experimental EXAFS data contain sufficient amount of such information. Note that an accurate theoretical description of the EXAFS spectrum is crucial for such study and should include both contributions from distant coordination shells and many-atom correlations, appearing as multiple-scattering (MS) effects. Such simulations are possible nowadays due to the widespread availability of high performance computing systems [61]. We have also demonstrated recently that significant reduction in the required computational resources for RMCEXAFS calculations can be ensured, if RMC process is complemented by evolutionary algorithm, allowing a very efficient structural model optimization [48].

The details of RMC/EA approach for EXAFS analysis are given in our papers [48, 62].

In this study, the equilibrium structure of $\mathrm{Cu}_{3} \mathrm{~N}$ with the lattice parameter $a_{0}=3.819 \AA$, known from diffraction experiments [20], was used as initial configuration for RMC/EA simulations, performed for the $4 a_{0} \times 4 a_{0} \times 4 a_{0}$ supercell, containing 256 atoms. Similarly, for RMC simulations of the $\mathrm{Cu} \mathrm{K}$-edge EXAFS spectra of metallic copper the $4 a_{0} \times 4 a_{0} \times 4 a_{0}$ supercell, containing 256 atoms, was used with the lattice parameter $a_{0}=3.615 \AA$ [63]. Periodic boundary conditions were employed to avoid surfacerelated effects. The lattice parameter was not varied during the simulations, hence ensuring that the average structure of $\mathrm{Cu}_{3} \mathrm{~N}$ and metallic $\mathrm{Cu}$ is in agreement with the experimental diffraction data. For ab-initio calculations of the $\mathrm{Cu} \mathrm{K}$-edge EXAFS spectra we used real-space MS self-consistent FEFF8.5L code [64]. Scattering paths with the half-length $R$ of up to $7.0 \AA$ were determined for each atomic configuration and included in the calculations, thus the MS effects with up to eight scatterers were taken into
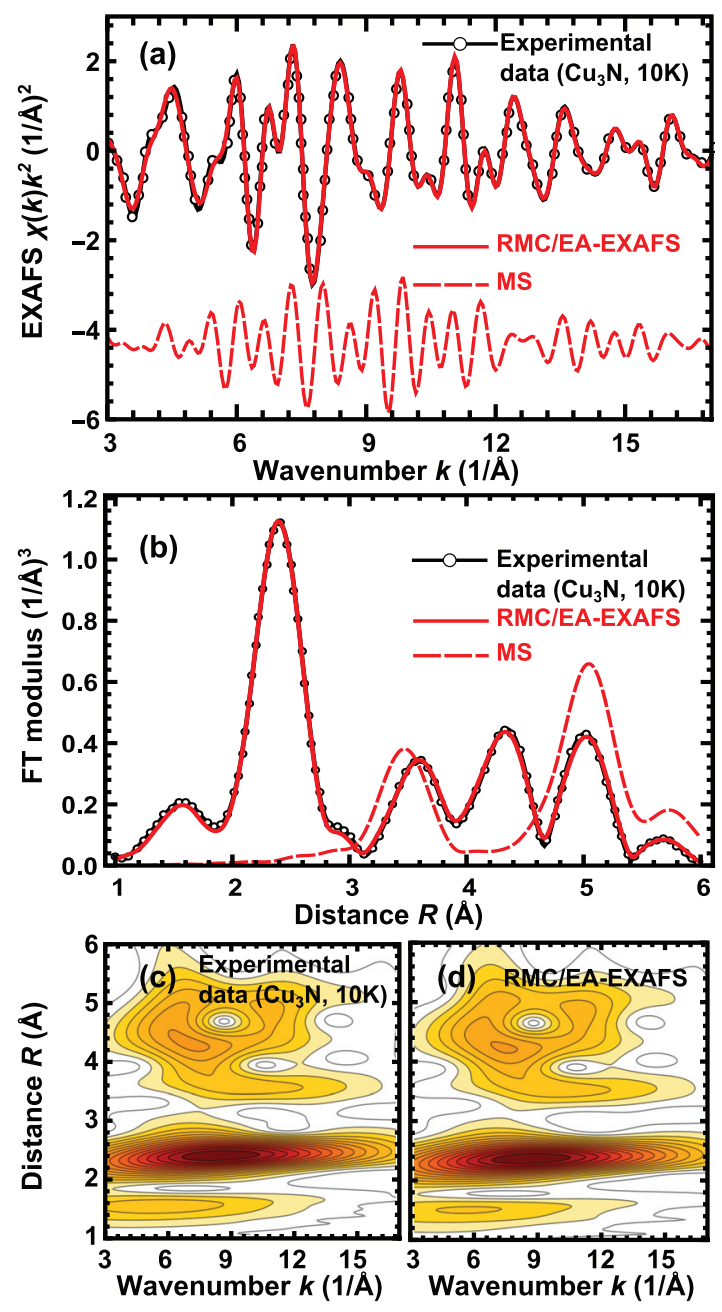

Figure 2: (Color online) Comparison of the experimental $(T=10 \mathrm{~K}$ ) and calculated configuration-averaged $\mathrm{Cu}$ K-edge EXAFS spectra of $\mathrm{Cu}_{3} \mathrm{~N}(\mathrm{a})$ and their Fourier (b) and Morlet wavelet (c, d) transforms. Dashed lines in panel (a) and (b) show the multiple-scattering contribution to the total calculated EXAFS spectrum and its FT. Spectra in panel (a) are shifted vertically for clarity.

account. For comparison of experimental and theoretical EXAFS data, required at each RMC/EA iteration, we relied on the Morlet wavelet transform [51]. More technical details are given in [55].

\section{Data analysis}

The atomic coordinates derived from the final RMC/EA configuration can be used to calculate structural parameters of interest. In particular, one can calculate the radial distribution functions (RDF) of atoms of different types, average interatomic distances for $i$-th coordination shell $R_{i}$ , second moments of bond length distributions $\sigma_{i}^{2}$, which account for thermal and static disorder [45], etc. Note that $\sigma_{i}^{2}$ values mostly characterize the mean-square relative displacements (MSRD) of atoms in the direction, parallel to the interatomic bond $\left(\sigma^{2} \approx \mathrm{MSRD}_{\|}\right)[46]$. MSRDs in the direction, perpendicular to the bond direction $\left(\mathrm{MSRD}_{\perp}\right)$, 
in turn, can be obtained by comparing the distance $R_{i}^{\text {eq }}$ between the equilibrium positions of corresponding atoms, with the average interatomic distance $R_{i}[46,65]$.

Here we define

$$
\mathrm{MSRD}_{\perp}=R_{i}^{\mathrm{eq}}\left(R_{i}-R_{i}^{\mathrm{eq}}\right)
$$

The analysis of $\mathrm{MSRD}_{\|}$and $\mathrm{MSRD}_{\perp}$ factors can provide information on interatomic interactions. The $\mathrm{MSRD}_{\|}$ factor for atoms $\mathrm{A}$ and $\mathrm{B}$ is related to the mean-square displacement (MSD) factors $\left\langle u_{\mathrm{A}}^{2}\right\rangle$ and $\left\langle u_{\mathrm{B}}^{2}\right\rangle$ in the bondparallel direction as [46]

$$
\operatorname{MSRD}_{\|}(A, B)=\left\langle u_{A}^{2}\right\rangle+\left\langle u_{B}^{2}\right\rangle-2 \rho \sqrt{\left\langle u_{A}^{2}\right\rangle\left\langle u_{B}^{2}\right\rangle}
$$

Here $\rho$ is the Pearson correlation coefficient. $\rho$ is equal to 0 for completely uncorrelated motion of atoms $\mathrm{A}$ and $\mathrm{B}$, and is equal to 1 for completely correlated in-phase motion of these atoms. Negative value of $\rho$ indicates the anticorrelated motion of atoms $\mathrm{A}$ and $\mathrm{B}$.

MSD factors usually are measured by diffraction techniques. We have, however, demonstrated that in some cases they can also be calculated in RMC/EA-EXAFS simulations [48, 49], thus avoiding problems that may arise, when results of two different experiments are combined. One can also use the atomic coordinates, obtained in RMC/ procedure, to calculate directly the interatomic correlations $\rho$.

Much moore extensive information on interatomic interactions can be obtained by analyzing the temperature dependencies of MSRD factors. Note that both static and thermal disorder contribute to MSRD values. The temperature dependence of disorder can be described by the correlated Einstein model [45, 46, 66]

$$
\operatorname{MSRD}(T)=\sigma_{S}^{2}+\frac{\hbar}{2 \mu \omega} \operatorname{coth} \frac{\hbar \omega}{2 k_{B} T}
$$

where $\sigma_{S}^{2}$ is static disorder contribution, $\mu$ is the effective mass of the atomic pair, $k_{B}$ is the Boltzmann constant and $\omega$ is the Einstein frequency, which corresponds to some effective atomic vibration frequency in the given direction and depends on the strength of interatomic interactions. At high temperatures the model predicts linear increase of the MSRD factor with the slope of $\operatorname{MSRD}(T)$ function determined by the effective force constant $\kappa=\mu \omega^{2}$.The ratio of effective force constants $\kappa_{\|}$and $\kappa_{\perp}$, obtained from temperature dependencies of $\mathrm{MSRD}_{\|}$and $\mathrm{MSRD}_{\perp}$, respectively, defined as $\gamma=\left(\kappa_{\|} / \kappa_{\perp}\right)^{1 / 2}$ can be used as a convenient and robust measure of the anisotropy of relative atomic motion [46].

\section{Results and discussion}

\subsection{Experimental EXAFS data}

Fourier transforms of the experimental $\mathrm{Cu}$ K-edge EXAFS spectra of $\mathrm{Cu}_{3} \mathrm{~N}$ (Fig. 1) show clearly that atoms located as far as up to $10 \AA$ from the absorbing copper contribute to the EXAFS spectrum, especially at low temperatures. The distant FT peaks become strongly suppressed upon temperature increase due to thermal disorder effect. Nevertheless, contributions from atoms located up to $6 \AA$ from the absorbing copper are still observed up to room temperature and, therefore, were analyzed.

The first two prominent FT peaks at $R \sim 1.5 \AA$ and $\sim 2.5 \AA$ in Fig. 1 are mostly due to the single-scattering (SS) contributions from the first $\left(\mathrm{Cu}_{0}-\mathrm{N}_{1}\right)$ and second $\left(\mathrm{Cu}_{0}-\mathrm{Cu}_{2}\right)$ coordination shells of copper, respectively. Note that the $\mathrm{Cu}-\mathrm{Cu}$ contribution depends strongly on temperature: the intensity of the corresponding peak in FT reduces significantly upon heating. On the contrary, the contribution of the first coordination shell $(\mathrm{Cu}-\mathrm{N}$ pair) is almost temperature independent. This implies strong correlations in the motion of neighboring atoms in this material.

More distant FT peaks in Fig. 1 are a result of complex superposition of the SS contributions from outer coordination shells and of all MS contributions. In particular, the MS processes within the linear atomic chains (such as $\mathrm{N}-\mathrm{Cu}-\mathrm{N}-$ chain, see the inset in Fig. 1) are expected to be important in perovskite-type structures [67, 68]. Hence A the conventional analysis of these peaks is challenging.

\subsection{Comparison of simulated and experimental EXAFS data}

The results of RMC/EA simulations for the $\mathrm{Cu}$ K-edge EXAFS of $\mathrm{Cu}_{3} \mathrm{~N}$ in the temperature range from $10 \mathrm{~K}$ to $300 \mathrm{~K}$ are shown in Figs. 2 and 3. Good agreement between the experimental and theoretical spectra was obtained at all temperatures. Note that this indicates that our model of stoichiometric, defect-free $\mathrm{Cu}_{3} \mathrm{~N}$ crystal does not contradict the available experimental EXAFS data, and there is no evidence of $\mathrm{Cu}_{3} \mathrm{~N}$ decomposition or metallization upon temperature increase from $10 \mathrm{~K}$ up to $300 \mathrm{~K}$. For comparison, we also show the results obtained using RMC/EA simulations for metallic copper at room temperature. Also in this case a good agreement between the experimental and theoretical EXAFS spectra is achieved (Fig. 3).

EXAFS spectrum obtained in the RMC/EA simulation for $\mathrm{Cu}_{3} \mathrm{~N}$ at $10 \mathrm{~K}$ (Fig. 2) was analyzed in more details. In particular, we used the final set of atomic coordinates, obtained in RMC/EA simulation and shown in the inset in Fig. 4, to calculate partial contribution of the MS effects to the total EXAFS spectrum. As expected, the MS effects appear to be very important for the material with cubic lattice such as $\mathrm{Cu}_{3} \mathrm{~N}$. In fact, the contribution of MS effects is dominating over the SS processes in the FT ranges from 3 to $4 \AA$ and above $4.5 \AA$. This is an important finding for further analysis, since contributions of the MS effects are related to many-atom distribution functions. Large MS contributions imply that experimental EXAFS spectra contain significant amount of information on distributions of bonding angles and interatomic correlations. 

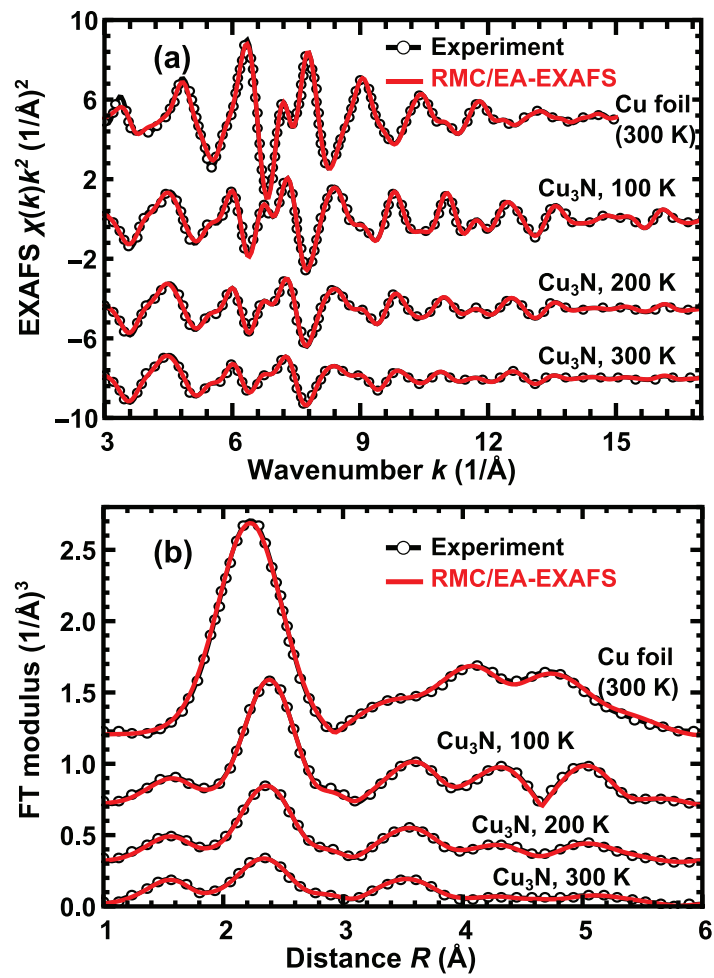

Figure 3: (Color online) Comparison between the experimental (open circles) and calculated (solid lines) $\mathrm{Cu}$ K-edge EXAFS spectra (a) and their Fourier transforms (b) for metallic copper at $300 \mathrm{~K}$ and for $\mathrm{Cu}_{3} \mathrm{~N}$ at 100, 200 and $300 \mathrm{~K}$. Calculated configuration-averaged $\mathrm{Cu}$ K-edge EXAFS spectra correspond to the final RMC/EA configuration. Plots are shifted vertically for clarity.

\subsection{Radial distribution functions}

Final set of atomic coordinates, obtained in RMC/EA simulations of the $\mathrm{Cu}$ K-edge EXAFS spectra of $\mathrm{Cu}_{3} \mathrm{~N}$ at different temperatures and of metallic copper at room temperature, were used to calculate partial radial distribution functions (RDFs) $g_{\mathrm{Cu}-\mathrm{N}}(R)$ and $g_{\mathrm{Cu}-\mathrm{Cu}}(R)$.

Reconstructed RDFs for $\mathrm{Cu}_{3} \mathrm{~N}$ and metallic copper at $10 \mathrm{~K}$ and $300 \mathrm{~K}$ are shown in Fig. 4 together with their structure models at $10 \mathrm{~K}$, presented in the insets.

Comparing the results for $\mathrm{Cu}_{3} \mathrm{~N}$ at $10 \mathrm{~K}$ and $300 \mathrm{~K}$, one can see that the effect of thermal disorder varies significantly in different coordination shells. The shape and position of the first peak, corresponding to the bond $\mathrm{Cu}_{0}-\mathrm{N}_{1}$ (see the scheme in Fig. 5), depend weakly on temperature, in agreement with previously observed insensitivity of the contribution from the first coordination shell to the total EXAFS spectrum towards temperature increase. At the same time, other RDF peaks (including the ones due to more distant nitrogen containing coordination shells) are broadened significantly upon temperature increase, suggesting that the amplitudes of atomic thermal vibrations increase strongly upon heating from $10 \mathrm{~K}$ up to $300 \mathrm{~K}$.

Comparison of RDFs obtained for $\mathrm{Cu}_{3} \mathrm{~N}$ and metallic copper is instructive to show the similarities in the arrangements of copper atoms in these two materials. Oneto-one correspondence of $\mathrm{Cu}-\mathrm{Cu} \mathrm{RDF}$ peaks can be found

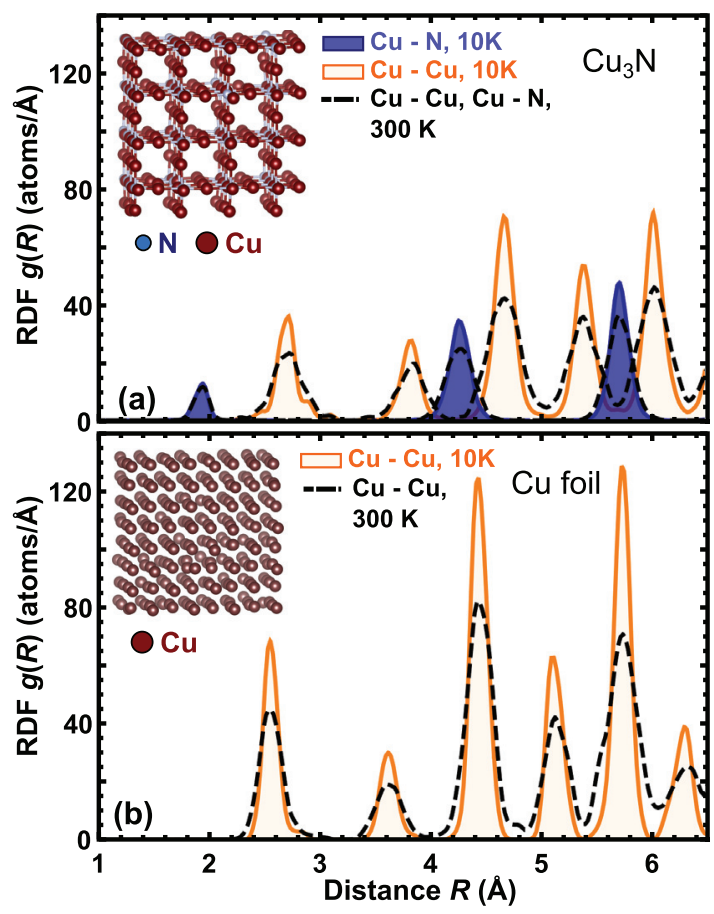

Figure 4: (Color online) Results of RMC/EA simulations for $\mathrm{Cu}_{3} \mathrm{~N}$ (a) and for metallic copper (b) at $10 \mathrm{~K}$ : the final structure models and partial $\mathrm{Cu}-\mathrm{Cu}$ and $\mathrm{Cu}-\mathrm{N}$ radial distribution functions (RDFs). The partial $\mathrm{Cu}-\mathrm{Cu}$ and $\mathrm{Cu}-\mathrm{N}$ RDFs at $300 \mathrm{~K}$ are also shown for comparison by dashed lines.

for these two systems for $R$ values at least up to $6 \AA$, taking into account small difference in their lattice parameters: $a_{0}=3.819 \AA$ for $\mathrm{Cu}_{3} \mathrm{~N}$ and $a_{0}=3.615 \AA$ for metallic copper. The intensities of RDF peaks for $\mathrm{Cu}_{3} \mathrm{~N}$ and metallic copper differ due to the fact that in $\mathrm{Cu}_{3} \mathrm{~N}$ the number of copper atoms per volume unit is smaller than in the close-packed fcc structure of metallic copper. The relative change in the peak intensities due to the temperature increase is comparable in $\mathrm{Cu}_{3} \mathrm{~N}$ and metallic copper.

\subsection{MSRD factors and effective force constants}

The temperature dependencies of parallel and perpendicular MSRD factors were calculated for the first seven coordination shells of copper and are shown in Figs. 5 and 6. The obtained $\operatorname{MSRD}(T)$ functions were fitted using the correlated Einstein model [66], and effective force constants $\kappa$ and static disorder factors $\sigma_{S}^{2}$ were estimated for the vibration of atoms in the directions parallel and perpendicular to the interatomic bond [46]. These quantities are summarized in Table 1.

Further we will examine separately the values of the structural parameters corresponding to atomic pairs that are located within linear $-\mathrm{N}-\mathrm{Cu}-\mathrm{N}-$ chains and of the structural parameters for atom pairs in the off-chain positions. We will see that these parameters and their temperature dependencies are essentially different due to the anisotropy of atomic vibrations and interatomic interactions in $\mathrm{Cu}_{3} \mathrm{~N}$. 
Table 1: Effective force constants $\left(k_{\|}\right.$and $\left.k_{\perp}\right)$, anisotropy parameter $\gamma=\left(\kappa_{\|} / \kappa_{\perp}\right)^{1 / 2}$ and static disorder factors for atomic displacements along the bond $\left(\sigma_{S, \|}^{2}\right)$ and in bond-perpendicular direction $\left(\sigma_{S, \perp}^{2}\right)$ for $\mathrm{Cu}_{3} \mathrm{~N}$.

\begin{tabular}{|c|c|c|c|c|c|c|}
\hline & $R_{\text {eq }} / a_{0}$ & $k_{\|}(\mathrm{N} / \mathrm{cm})$ & $k_{\perp}(\mathrm{N} / \mathrm{cm})$ & $\gamma$ & $\sigma_{S, \|}^{2}\left(\AA^{2}\right)$ & $\sigma_{S, \perp}^{2}\left(\AA^{2}\right)$ \\
\hline $\mathrm{Cu}_{0}-\mathrm{N}_{1}$ & $1 / 2$ & $1.48(4)$ & $0.32(2)$ & $2.2(1)$ & $0.000(1)$ & $0.002(1)$ \\
\hline $\mathrm{Cu}_{0}-\mathrm{Cu}_{2}$ & $1 / \sqrt{2}$ & $0.28(1)$ & $0.31(2)$ & $0.95(4)$ & $0.002(1)$ & $0.006(1)$ \\
\hline $\mathrm{Cu}_{0}-\mathrm{Cu}_{3 a}$ & 1 & $1.0(3)$ & $0.30(3)$ & $1.8(2)$ & $0.004(1)$ & $0.006(1)$ \\
\hline $\mathrm{Cu}_{0}-\mathrm{Cu}_{3 b}$ & 1 & $0.23(1)$ & $0.51(6)$ & $0.67(6)$ & $0.002(1)$ & $0.008(1)$ \\
\hline $\mathrm{Cu}_{0}-\mathrm{N}_{4}$ & $\sqrt{5} / 2$ & $0.28(4)$ & $0.44(3)$ & $0.80(3)$ & $0.000(1)$ & $0.002(1)$ \\
\hline $\mathrm{Cu}_{0}-\mathrm{Cu}_{5}$ & $\sqrt{6} / 2$ & $0.23(1)$ & $0.38(2)$ & $0.77(4)$ & $0.003(1)$ & $0.007(1)$ \\
\hline $\mathrm{Cu}_{0}-\mathrm{Cu}_{6}$ & $\sqrt{2}$ & $0.25(1)$ & $0.36(2)$ & $0.84(5)$ & $0.003(1)$ & $0.007(1)$ \\
\hline $\mathrm{Cu}_{0}-\mathrm{N}_{7 a}$ & $3 / 2$ & $0.54(4)$ & $0.32(1)$ & $1.29(7)$ & $0.000(1)$ & $0.001(1)$ \\
\hline $\mathrm{Cu}_{0}-\mathrm{N}_{7 b}$ & $3 / 2$ & $0.33(1)$ & $0.42(3)$ & $0.88(5)$ & $0.000(1)$ & $0.002(1)$ \\
\hline
\end{tabular}

The atom pairs $\mathrm{Cu}_{0}-\mathrm{N}_{1}$, composed of nitrogen atoms located in the first coordination shell, have the shortest interatomic distance within $-\mathrm{N}-\mathrm{Cu}-\mathrm{N}-$ chains. As shown in Fig. 5(a), next in-chain pairs include atoms of the 3rd coordination shell $\left(\mathrm{Cu}_{0}-\mathrm{Cu}_{3}\right)$ and of the 7 th coordination shell $\left(\mathrm{Cu}_{0}-\mathrm{N}_{7}\right)$. Note, however, that not all atoms in the 3rd and 7 th coordination shells belong to $-\mathrm{N}-\mathrm{Cu}-\mathrm{N}-$ chains. There are six copper atoms in the 3rd coordination shell, which all are located in the equilibrium structure at the distance $R=a_{0}$ from the $\mathrm{Cu}_{0}$ atom. Only two of these atoms, however, belong to the same $-\mathrm{N}-\mathrm{Cu}-\mathrm{N}-$ chain as $\mathrm{Cu}_{0}$. The remaining four $\mathrm{Cu}$ atoms belong to neighboring $\mathrm{NCu}_{6}$ octahedra. Similarly, the 7 th coordination shell with equilibrium $\mathrm{Cu}-\mathrm{N}$ distance equal to $1.5 a_{0}$ consists of two nitrogen atoms in the in-chain positions with respect to $\mathrm{Cu}_{0}$ and of four nitrogen atoms in the off-chain positions. We will denote the atom pairs in the 3rd and 7th coordination shells that are located within $-\mathrm{N}-\mathrm{Cu}-\mathrm{N}-$ chain as $\mathrm{Cu}_{0}-\mathrm{Cu}_{3 a}$ and $\mathrm{Cu}_{0}-\mathrm{N}_{7 a}$, correspondingly, while the offchain atom pairs will be denoted as $\mathrm{Cu}_{0}-\mathrm{Cu}_{3 b}$ and $\mathrm{Cu}_{0^{-}}$ $\mathrm{N}_{7 b}$. As one can see in Fig. 5, despite the fact that crystallographic bond lengths corresponding to $\mathrm{Cu}_{0}-\mathrm{Cu}_{3 a}$ and $\mathrm{Cu}_{0}-\mathrm{Cu}_{3 b}$ atom pairs (and $\mathrm{Cu}_{0}-\mathrm{N}_{7 a}$ and $\mathrm{Cu}_{0}-\mathrm{N}_{7 b}$ atom pairs) are the same, the MSRD factors for these pairs and their temperature dependencies are different. Note also, that separate analysis of contributions of these pairs is possible only employing such simulation-based approach as RMC method.

For comparison, in Figs. 5 and 6 we show also the $\mathrm{Cu}-$ $\mathrm{Cu}$ MSRD factors obtained in the RMC simulations for metallic copper. Note that these results are in excellent agreement both with the results of conventional analysis of EXAFS data and with the results of path-integral Monte Carlo simulations [69, 70].

Anisotropy of atomic motion. Parallel MSRD factor for $\mathrm{Cu}_{0}-\mathrm{N}_{1}$ atom pair has the smallest value, and it is also increasing slowly upon temperature increase (see Fig. 5). Weaker temperature dependencies of parallel MSRD factors are observed also for other atomic pairs that are located within single $-\mathrm{N}-\mathrm{Cu}-\mathrm{N}-$ chain. For perpendicular MSRDs (Fig. 6), in turn, the opposite is true: MSRD $\perp$ factors increase more rapidly for in-chain atom pairs than for their off-chain counterparts. These findings are in agree- ment with expected anisotropy of copper motion, as observed for $\mathrm{Cu}_{3} \mathrm{~N}$ in diffraction studies [20, 21]: the vibrations of copper atoms in the direction orthogonal to $-\mathrm{N}-$ $\mathrm{Cu}-\mathrm{N}-$ chains are significantly larger than their vibrations along the chains, and they also grow faster upon increasing temperature. Note that similar trends have been observed by us previously in perovskite-type $\mathrm{ReO}_{3}[48,49,14]$ and $\mathrm{ScF}_{3}[38]$.

We can use the anisotropy parameter $\gamma=\left(\kappa_{\|} / \kappa_{\perp}\right)^{1 / 2}$, as introduced in [46], to characterize the anisotropy of the relative $\mathrm{Cu}$ and $\mathrm{N}$ vibrations quantitatively. The obtained value of $\gamma$ for $\mathrm{Cu}_{0}-\mathrm{N}_{1}$ atom pair is 2.2(1), which indicates that at high-temperatures the relative amplitude of $\mathrm{Cu}$ vibrations is twice larger in the direction perpendicular to the $-\mathrm{N}-\mathrm{Cu}-\mathrm{N}-$ chain. This value is larger than the corresponding value for the first coordination shell in $\mathrm{ReO}_{3}(\gamma \sim 1.6[52,14])$. Note that similarly large value $(\gamma=1.8(2))$ for anisotropy parameter was obtained also for $\mathrm{Cu}_{0}-\mathrm{Cu}_{3 a}$ atom pair in $\mathrm{Cu}_{3} \mathrm{~N}$.

The value of $\gamma$, obtained for $\mathrm{Cu}_{0}-\mathrm{N}_{7 a}$ atom pair, appears to be slightly smaller than the one for $\mathrm{Cu}_{0}-\mathrm{N}_{1}$ atom pair. This finding implies that the correlations in the motion of $\mathrm{Cu}$ and $\mathrm{N}$ atoms along $-\mathrm{N}-\mathrm{Cu}-\mathrm{N}-$ chain are reduced in more distant coordination shells.

For the shortest $\mathrm{Cu}_{0}-\mathrm{Cu}_{2}$ distance the vibrations of $\mathrm{Cu}$ atoms along bond direction and in the perpendicular direction have the same amplitudes, as evidenced by corresponding $\gamma$ value equal to $0.95(4)$, being close to 1 . Interestingly that this value of the parameter $\gamma$ is quite close to that $(\gamma \sim 1.1)$, obtained for metallic copper [46]. At the same time, both parallel and perpendicular MSRD values for $\mathrm{Cu}_{0}-\mathrm{Cu}_{2}$ atom pair are larger than the ones for the nearest neighbors in metallic copper.

So far we have discussed relative atomic motion only, hence the observed anisotropy of MSRD factors can be a result of anisotropy of thermal ellipsoids as well as of the anisotropy in the interatomic interactions, which makes the motion of atoms more correlated in specific directions. To distinguish between these two cases, we need either to compare the values of MSRD factors with the corresponding values of MSD factors (see Section 5.5) or to calculate correlation factors directly from atomic coordinates (see Section 5.6). 


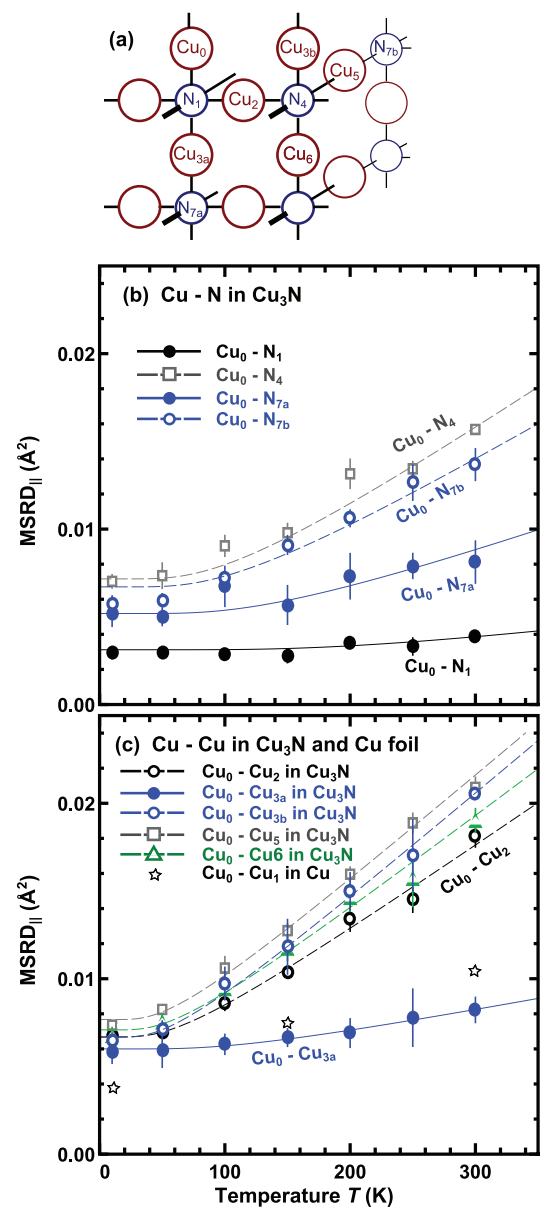

Figure 5: (Color online) (a) A fragment of the $\mathrm{Cu}_{3} \mathrm{~N}$ structure. Atoms of the nearest seven coordination shells around the absorbing copper $\mathrm{Cu}_{0}$ are indicated. Temperature dependencies of the parallel MSRD factors for $\mathrm{Cu}-\mathrm{N}$ (b) and $\mathrm{Cu}-\mathrm{Cu}$ (c) atom pairs in the first seven coordination shells in $\mathrm{Cu}_{3} \mathrm{~N}$. Solid symbols refer to the atom pairs within single $-\mathrm{N}-\mathrm{Cu}-\mathrm{N}-$ chain, while open symbols - to the atoms in the off-chain positions. The data for the nearest neighbours in metallic copper are shown for comparison by open asterisks. Solid and dashed lines are the fits by the correlated Einstein model for atom pairs within single $-\mathrm{N}-\mathrm{Cu}-\mathrm{N}-$ chain and in the off-chain positions, respectively.

Static disorder in $C u-N$ bonds. Large value of the effective force constant $\kappa_{\|}$for $\mathrm{Cu}_{0}-\mathrm{N}_{1}$ atom pairs suggests that $\mathrm{NCu}_{6}$ octahedra can be considered as relatively rigid units. Regularity of these structural units is implied by the small value of static disorder $\sigma_{S}^{2}$ (Table 1 ): when the temperature dependence of the $\mathrm{Cu}_{0}-\mathrm{N}_{1}$ parallel MSRD is fitted by the correlated Einstein model [66], the contribution of static disorder $\sigma_{S}^{2}$ is negligible within the accuracy of our analysis. Small values of $\sigma_{S}^{2}$ are also observed for more distant $\mathrm{Cu}-\mathrm{N}$ atom pairs. At the same time, the static disorder $\sigma_{S}^{2}$ is slightly larger for $\mathrm{Cu}-\mathrm{Cu}$ atom pairs as well as in perpendicular directions. A possible interpretation of such differences in $\sigma_{S}^{2}$ term for $\mathrm{MSRD}_{\perp}$ and $\mathrm{MSRD}_{\|}$is that $\mathrm{Cu}_{3} \mathrm{~N}$ consists of regular $\mathrm{NCu}_{6}$ units, but these units are slightly and randomly tilted, resulting in buckling of $-\mathrm{N}-\mathrm{Cu}-\mathrm{N}-$ chains. Note that if the tilting of neighboring

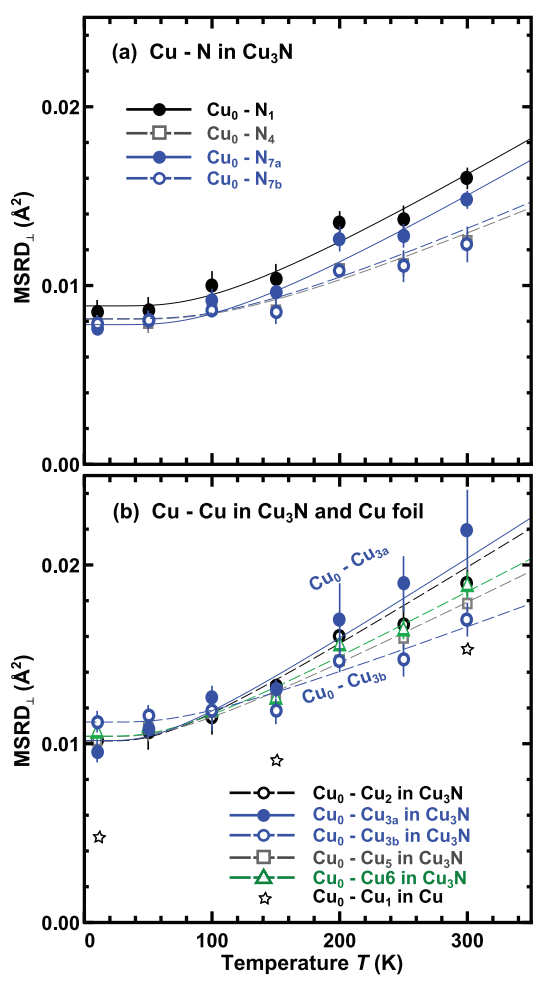

Figure 6: (Color online) Temperature dependencies of the perpendicular MSRD factors for $\mathrm{Cu}-\mathrm{N}$ (a) and $\mathrm{Cu}-\mathrm{Cu}$ (b) atom pairs in the first seven coordination shells in $\mathrm{Cu}_{3} \mathrm{~N}$. Solid symbols refer to the atom pairs within single $-\mathrm{N}-\mathrm{Cu}-\mathrm{N}-$ chain, while open symbols - to the atoms in the off-chain positions. The data for the nearest neighbours in metallic copper are shown for comparison by open asterisks. Solid and dashed lines are the fits by the correlated Einstein model for atom pairs within single $-\mathrm{N}-\mathrm{Cu}-\mathrm{N}-$ chain and in the off-chain positions, respectively.

octahedra is not correlated, the average structure of $\mathrm{Cu}_{3} \mathrm{~N}$, as probed by diffraction methods, still would appear as cubic.

\subsection{MSD factors}

MSD factors for $\mathrm{Cu}$ and $\mathrm{N}$ atoms were calculated from the coordinates of atoms in the final structure models, obtained in RMC/EA-EXAFS simulations, and are shown in Fig. 7. For comparison, we also present here the MSD values, obtained from diffraction studies [20, 21]. Note that to our knowledge, diffraction-based analysis of MSD factors for $\mathrm{Cu}_{3} \mathrm{~N}$ was performed at room [20, 21] and liquid nitrogen [20] temperatures only, hence our results, covering broader temperature range, complement the available information.

As for MSRD factors, the Einstein model can be used to fit the temperature dependencies of MSD factors. The results of these fits are shown as solid lines in Fig. 7. The corresponding Einstein frequencies can be used to calculate effective force constants $\kappa_{\mathrm{MSD}}$, which can be employed to characterize in harmonic approximation the shape of the potential, determining the thermal vibration of atoms. For diffraction data, where MSD values are available only at two temperatures, one can estimate $\kappa_{\mathrm{MSD}}$ as $\kappa_{\mathrm{MSD}}=$ 


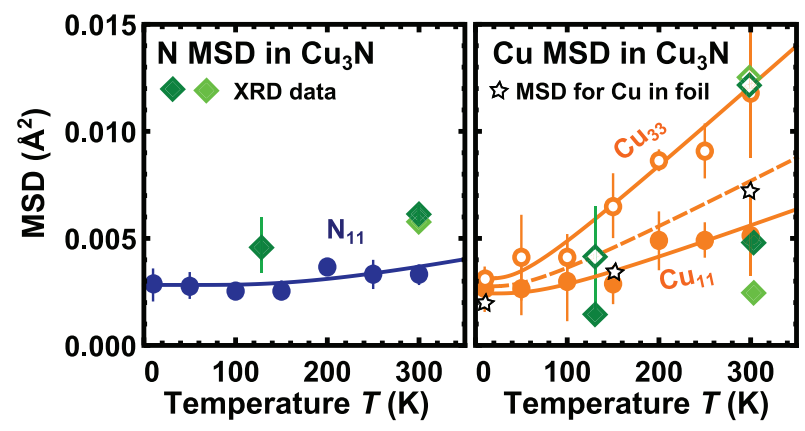

Figure 7: (Color online) Temperature dependencies of anisotropic MSD factors for $\mathrm{N}$ and $\mathrm{Cu}$ atoms in $\mathrm{Cu}_{3} \mathrm{~N} . \mathrm{Cu}_{11}$ correspond to $\left\langle u_{11}^{2}\right\rangle$ MSD factor of copper, $\mathrm{Cu}_{33}$ correspond to $\left\langle u_{22}^{2}\right\rangle=\left\langle u_{33}^{2}\right\rangle$ MSD factors of copper, $\mathrm{N}_{11}$ correspond to $\left\langle u_{11}^{2}\right\rangle=\left\langle u_{22}^{2}\right\rangle=\left\langle u_{33}^{2}\right\rangle$ MSD factors of nitrogen. Solid lines show the fits by the Einstein model. Dashed line shows the calculated $2\left(1 /\left\langle u_{11}^{2}\right\rangle+1 /\left\langle u_{33}^{2}\right\rangle\right)^{-1}$ value, which corresponds to the MSD factor in the direction of bond between two nearest $\mathrm{Cu}$ atoms. Diamonds show results from diffraction experiments [21] (light solid and open diamonds) and [20] (dark solid and open diamonds). The MSD values for $\mathrm{Cu}$ atoms in metallic copper are shown by open asterisks for comparison.

Table 2: Effective force constants $\kappa_{\mathrm{MSD}}$, calculated from MSD factors for $\mathrm{Cu}$ and $\mathrm{N}$ atoms in $\mathrm{Cu}_{3} \mathrm{~N}$. $\mathrm{Cu}_{11}$ correspond to $\left\langle u_{11}^{2}\right\rangle \mathrm{MSD}$ factor of copper, $\mathrm{Cu}_{33}$ corresponds to $\left\langle u_{22}^{2}\right\rangle=\left\langle u_{33}^{2}\right\rangle$ MSD factors of copper, $\mathrm{N}_{11}$ corresponds to $\left\langle u_{11}^{2}\right\rangle=\left\langle u_{22}^{2}\right\rangle=\left\langle u_{33}^{2}\right\rangle$ MSD factors of nitrogen.

\begin{tabular}{ccc}
\hline & $\kappa_{\mathrm{MSD}}(\mathrm{N} / \mathrm{cm})$ & $\kappa_{\mathrm{MSD}}(\mathrm{N} / \mathrm{cm})$ \\
& $($ from RMC/EA-EXAFS) & (from diffraction [20]) \\
\hline $\mathrm{Cu}_{11}$ & $0.9(3)$ & $\sim 0.7$ \\
$\mathrm{Cu}_{33}$ & $0.36(3)$ & $\sim 0.29$ \\
$\mathrm{~N}_{11}$ & $1.5(1)$ & $\sim 1.8$ \\
\hline
\end{tabular}

$\left(k_{B} \Delta T\right) /\left(\Delta\left\langle u^{2}\right\rangle\right)$, where $\Delta\left\langle u^{2}\right\rangle$ is the difference in MSD factors, obtained at temperatures $T$ and $T+\Delta T$. The values of effective force constants $\kappa$, obtained from RMC/EAEXAFS and diffracton, are summarized in Table 2.

At temperatures where both RMC/EA-EXAFS and diffraction data are available, our MSD values for nitrogen and copper atoms in $\mathrm{Cu}_{3} \mathrm{~N}$ are in a reasonable agreement with diffraction results. The vibration amplitude of nitrogen atoms is isotropic, hence the amplitudes of atomic displacements in three orthogonal directions, as determined by MSD factors $\left\langle u_{11}^{2}\right\rangle,\left\langle u_{22}^{2}\right\rangle$ and $\left\langle u_{33}^{2}\right\rangle$, are equal and depend weakly on temperature. The thermal ellipsoids of copper, in turn, are essentially anisotropic, especially at high temperatures, and copper vibrations along $-\mathrm{N}-\mathrm{Cu}-$ $\mathrm{N}$ - chain $\left(\left\langle u_{11}^{2}\right\rangle\right.$ factors $)$ are significantly smaller than the copper vibrations in two orthogonal directions $\left(\left\langle u_{22}^{2}\right\rangle\right.$ and $\left\langle u_{33}^{2}\right\rangle$ factors). At temperatures close to $0 \mathrm{~K}$, however, the amplitudes of copper vibrations in different directions are quite close.

Note that for copper the uncertainty of the obtained MSD values is quite large, but also the MSD values from two different diffraction studies [20,21] are different, especially for $\mathrm{Cu}_{11}$ MSD factors.

Nevertheless, when the estimated effective force constants $\kappa_{\mathrm{MSD}}$ are compared (Table 2), a good agreement between the results of RMC/EA-EXAFS simulations and diffraction data is observed. This indicates that the changes in the MSD factors due to temperature increase are recovered by our method with a reasonable accuracy.

By comparing the results shown in Figs. 5 and 7, one can see immediately, for instance, that the sum of $\left\langle u_{11}^{2}\right\rangle$ factors for $\mathrm{N}$ and $\mathrm{Cu}$ in $\mathrm{Cu}_{3} \mathrm{~N}$ is about twice as large as the value of the parallel MSRD factor for $\mathrm{Cu}_{0}-\mathrm{N}_{1}$ bond. This is the direct indication that correlation effects play an important role in this material [46].

In Fig. 7 we also show the MSD factor for $\mathrm{Cu}$ atoms in metallic copper, as obtained from our RMC/EA simulations. At $300 \mathrm{~K}$ the $\mathrm{MSD}$ value $\left\langle u_{11}^{2}\right\rangle=\left\langle u_{22}^{2}\right\rangle=\left\langle u_{33}^{2}\right\rangle=$ $0.0072(3) \AA^{2}$ is in a good agreement with literature data [71] $\left(\sim 0.007 \AA^{2}\right)$. Note that this value is also close to $2\left(1 /\left\langle u_{11}^{2}\right\rangle+1 /\left\langle u_{33}^{2}\right\rangle\right)^{-1}$ value for copper in $\mathrm{Cu}_{3} \mathrm{~N}$, which corresponds to the MSD factor in the direction of the bond between two nearest $\mathrm{Cu}$ atoms. Hence the absolute amplitudes of copper thermal vibrations in these two materials are close. At the same time, as shown in Fig. 5(b), the MSRD values for pairs of nearest copper atoms in $\mathrm{Cu}_{3} \mathrm{~N}$ and metallic copper are quite different. These findings indicate significant differences in the correlations of motion of neighboring copper atoms. Further we will analyze the correlations in the motion of copper and nitrogen atoms in $\mathrm{Cu}_{3} \mathrm{~N}$ in more details.

\subsection{Interatomic correlation effects}

Correlation of atomic motion in $\mathrm{Cu}_{0}-\mathrm{N}_{1}, \mathrm{Cu}_{0}-\mathrm{Cu}_{2}$, $\mathrm{Cu}_{0}-\mathrm{Cu}_{3 a}$ and $\mathrm{Cu}_{0}-\mathrm{Cu}_{3 b}$ atom pairs in $\mathrm{Cu}_{3} \mathrm{~N}$ was described in terms of the parameter $\rho$ (see Eq. (2)), which was calculated directly from atomic coordinates and is plotted as a function of temperature in Fig. 8. The results obtained for atomic displacements in the direction of interatomic bond and for atomic displacements in the perpendicular direction are shown separately. In Fig. 8(a) we compare $\rho$ values for the bonds between atoms located at the octahedron center and at the vertex, i.e., for $\mathrm{Cu}_{0}-\mathrm{N}_{1}$ bond in $\mathrm{Cu}_{3} \mathrm{~N}$ and for $\mathrm{Re}-\mathrm{O}$ bond in $\mathrm{ReO}_{3}$ [48, 49, 52]. In Fig. 8(b) we compare $\rho$ values for the atom pairs forming octahedra edges, i.e., for $\mathrm{Cu}_{0}-\mathrm{Cu}_{2}$ bond in $\mathrm{Cu}_{3} \mathrm{~N}$ and for $\mathrm{O}-\mathrm{O}$ bond in $\mathrm{ReO}_{3}$. In addition, we present also the results for two nearest $\mathrm{Cu}$ atoms in metallic copper. In Fig. 8(c) and (d) we compare $\rho$ values for the copper pairs within $-\mathrm{N}-\mathrm{Cu}-\mathrm{N}-$ chain and copper pairs with the same equilibrium interatomic distance, but located in the offchain positions. For comparison, we show here also the results for corresponding $\mathrm{O}-\mathrm{O}$ pairs in $\mathrm{ReO}_{3}$.

First, strong correlation of atomic motion for neighboring $\mathrm{Cu}$ and $\mathrm{N}$ atoms in the direction of $-\mathrm{N}-\mathrm{Cu}-\mathrm{N}-$ chains is observed (Fig. 8(a)), as expected from the comparison of corresponding MSD and MSRD factors. The value of correlation parameter $\rho$ in this case is about 0.5 , and almost does not depend on temperature in the investigated temperature range. Note that the correlation for neighboring $\mathrm{Cu}$ and $\mathrm{N}$ atoms is close to that for neighboring $\mathrm{Re}$ and $\mathrm{O}$ atoms in perovskite-type $\mathrm{ReO}_{3}$. 


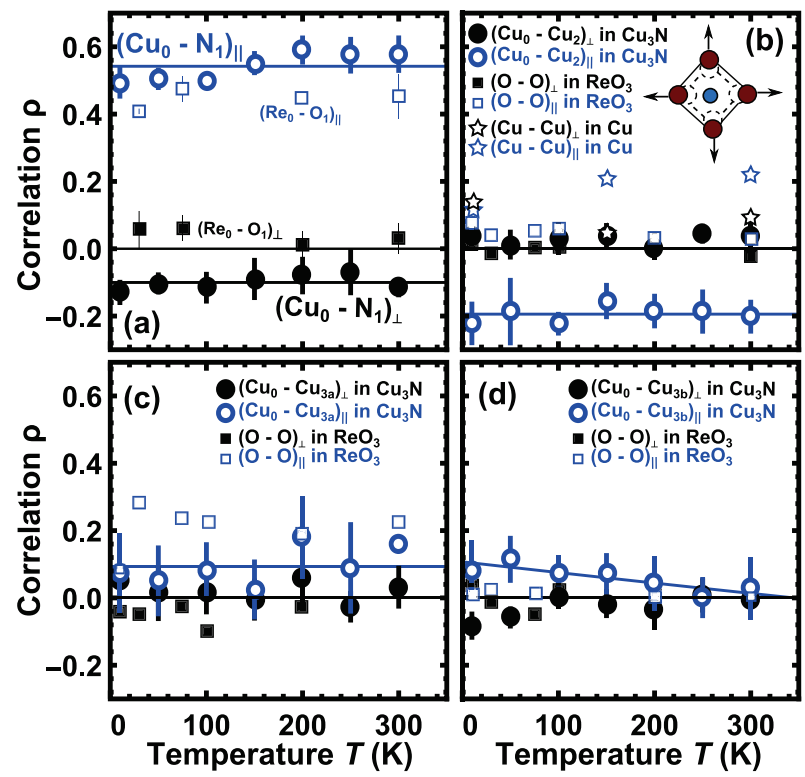

Figure 8: (Color online) Temperature dependencies of correlations $\rho$ in atomic motion in $\mathrm{Cu}_{0}-\mathrm{N}_{1}$ (a), $\mathrm{Cu}_{0}-\mathrm{Cu}_{2}$ (n), $\mathrm{Cu}_{0}-\mathrm{Cu}_{3 a}$ (c) and $\mathrm{Cu}_{0}-\mathrm{Cu}_{3 b}$ (d) pairs in $\mathrm{Cu}_{3} \mathrm{~N}$. Results, obtained for the motion of atoms in the direction of interatomic bond (open circles) and in the perpendicular direction (blue circles) are shown separately. Solid lines - guides for the eye. Open and solid rectangles show the results in the parallel and perpendicular directions, respectively, for the Re$\mathrm{O}$ and $\mathrm{O}-\mathrm{O}$ atom pairs in perovskite-type $\mathrm{ReO}_{3}[52,48,49]$. The results for neighboring $\mathrm{Cu}$ atoms in metallic copper are shown in (b) by asterisks. Schematic view of breathing vibration of $\mathrm{NCu}_{6}$ octahedra is shown in the inset in panel (b): it agrees with the observed correlation properties of $\mathrm{Cu}_{0}-\mathrm{Cu}_{2}$ pair in $\mathrm{Cu}_{3} \mathrm{~N}$.

Similarly to $\mathrm{ReO}_{3}$, the correlations in $\mathrm{Cu}_{3} \mathrm{~N}$ become weaker for more distant atoms within $-\mathrm{N}-\mathrm{Cu}-\mathrm{N}-$ chain. However, our analysis suggests that the correlation in the atomic motion decreases more rapidly for $\mathrm{Cu}_{3} \mathrm{~N}$ (for $\mathrm{Cu}_{0^{-}}$ $\mathrm{Cu}_{3 a}$ atoms $\rho$ value is 5 times smaller than that for $\mathrm{Cu}_{0}-\mathrm{N}_{1}$ pair). Thus the $-\mathrm{N}-\mathrm{Cu}-\mathrm{N}-$ chain can be considered as less rigid than $-\mathrm{Re}-\mathrm{O}-\mathrm{Re}-$ chains in $\mathrm{ReO}_{3}$. Moreover, when the atomic motion in $\mathrm{Cu}_{0}-\mathrm{Cu}_{3 a}$ and $\mathrm{Cu}_{0}-\mathrm{Cu}_{3 b}$ atom pairs in $\mathrm{Cu}_{3} \mathrm{~N}$ is compared (Fig. 8(c) and Fig. 8(d)), one can observe that at low temperatures the correlations for $\mathrm{Cu}_{0^{-}}$ $\mathrm{Cu}_{3 a}$ and $\mathrm{Cu}_{0}-\mathrm{Cu}_{3 b}$ pairs are comparable. Note that for $\mathrm{ReO}_{3}$ the correlations in the motion of $\mathrm{O}$ atoms within -O$\mathrm{Re}-\mathrm{O}-$ chain are much larger than the ones for pairs of $\mathrm{O}$ atoms at the same distances, but in the off-chain positions. Upon temperature increase, however, the correlation in the motion of $\mathrm{Cu}_{0}-\mathrm{Cu}_{3 b}$ pairs gradually decreases, while for $\mathrm{Cu}_{0}-\mathrm{Cu}_{3 b}$ pairs it is practically independent on temperature. This result shows the directional dependence of atomic interactions in $\mathrm{Cu}_{3} \mathrm{~N}$ material, and is in agreement with the results of ab-initio electronic structure calculations [39], indicated on the importance of covalent bonding in $\mathrm{Cu}_{3} \mathrm{~N}$.

Another interesting difference between $\mathrm{ReO}_{3}$ and $\mathrm{Cu}_{3} \mathrm{~N}$ is that the motion of neighboring $\mathrm{Cu}$ atoms in the direction of $\mathrm{Cu}-\mathrm{Cu}$ bond is significantly anticorrelated (Fig. 8(b)). In this case, the parameter $\rho$ is about -0.2 , and does
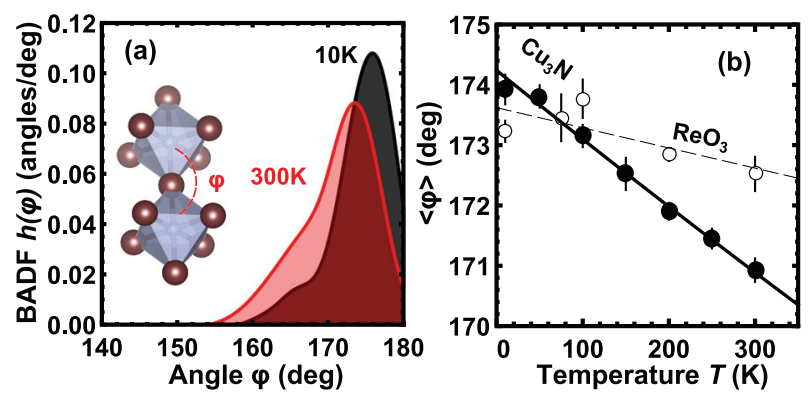

Figure 9: (Color online) (Color online) Temperature dependencies of (a) the $\mathrm{N}-\mathrm{Cu}-\mathrm{N}$ angle distribution and (b) the average $\mathrm{N}-\mathrm{Cu}-\mathrm{N}$ angle value (solid circles) in $\mathrm{Cu}_{3} \mathrm{~N}$. The values of the $\mathrm{Re}-\mathrm{O}-\mathrm{Re}$ angle in perovskite-type $\mathrm{ReO}_{3}$ (from [52]) are shown for comparison in (b). Solid and dashed lines - guides for the eye.

not change in the temperature range between $10 \mathrm{~K}$ and $300 \mathrm{~K}$. Such correlations cannot be observed in the motion of neighboring oxygen atoms in $\mathrm{ReO}_{3}$. Note that such correlations are not present also in the motion of neighboring atoms in metallic copper ( $\rho$ value for the latter has about the same absolute value, but the sign is opposite, indicating correlated, rather than anticorrelated motion). This difference in interatomic correlations explains the observed difference in MSRD factors for nearest $\mathrm{Cu}-\mathrm{Cu}$ pairs in $\mathrm{Cu}_{3} \mathrm{~N}$ and in metallic copper. Such anticorrelated motion of neighboring copper atoms in the direction parallel to $\mathrm{Cu}-\mathrm{Cu}$ bond in $\mathrm{Cu}_{3} \mathrm{~N}$ may be interpreted as a signature of breathing-type vibration of $\mathrm{NCu}_{6}$ octahedra [72] (see the inset in Fig. 8(b)).

Finally, note that within uncertainties of our analysis we found no correlations in the perpendicular motion of copper atoms in $\mathrm{Cu}_{3} \mathrm{~N}$. This fact distinguishes interactions between neighboring copper atoms in $\mathrm{Cu}_{3} \mathrm{~N}$ from those in metallic copper: for the latter small correlations in the perpendicular motion of neighboring $\mathrm{Cu}$ atoms can be detected. Interestingly, however, that we have found, instead, that the perpendicular motion of neighboring $\mathrm{Cu}$ and $\mathrm{N}$ atoms is weakly anticorrelated in $\mathrm{Cu}_{3} \mathrm{~N}$. This fact was not observed for nearest $\mathrm{Re}-\mathrm{O}$ pair in $\mathrm{ReO}_{3}$ structure, and should contribute to the buckling of $-\mathrm{N}-\mathrm{Cu}-\mathrm{N}-$ chain in $\mathrm{Cu}_{3} \mathrm{~N}$.

\subsection{Tilting angle}

Bonding angles are structural parameters that are closely related to interatomic correlations. In perovskite and antiperovskite-type structures the angle of particular interest is the angle $\varphi$ between vertex-sharing octahedral units $\left(\mathrm{NCu}_{6}\right.$ octahedra in our case, see the inset in Fig. 9). We have already pointed out in Section 5.4 that there are evidences in the behaviour of MSRD factors, indicating that static disorder is present in the arrangement of $\mathrm{NCu}_{6}$ units. In this Section, we discuss the changes in the $\varphi$ value due to thermal motion of atoms.

The obtained distributions of the $\varphi$ values in $\mathrm{Cu}_{3} \mathrm{~N}$ at $10 \mathrm{~K}$ and $300 \mathrm{~K}$ are compared in Fig. 9(a), while the average value of $\varphi$ as a function of temperature is plotted in 
Fig. 9(b). For comparison, we show here also the results for the corresponding $\mathrm{Re}-\mathrm{O}-\mathrm{Re}$ angle in $\mathrm{ReO}_{3}$ [52]. Note that $\langle\varphi\rangle$ value, as probed by EXAFS, is not the same as the angle between $\mathrm{NCu}_{6}$ octahedra in the average structure, as probed by diffraction studies [21]. The latter in cubic $\mathrm{Cu}_{3} \mathrm{~N}$ is equal to $180^{\circ}$ [21]. On the contrary, $\varphi$ value, as probed by EXAFS, is always smaller than $180^{\circ}$ due to relative thermal motion of atoms in the direction perpendicular to the $\mathrm{Cu}-\mathrm{N}$ atomic bonds [48].

Our results suggest that the distribution of $\varphi$ values at low temperature is narrow, and the average $\varphi$ value is even closer to $180^{\circ}$ than it was observed for $\mathrm{ReO}_{3}$. Hence, one can conclude that the tilting of $\mathrm{NCu}_{6}$ octahedra due to static disorder and thermal motion is relatively weak at low temperatures. At the same time, upon temperature increase the distribution of $\varphi$ values gets significantly broadened, and $\langle\varphi\rangle$ value decreases rapidly. At room temperature the value of $\langle\varphi\rangle$ for $\mathrm{N}-\mathrm{Cu}-\mathrm{N}$ bond angle in $\mathrm{Cu}_{3} \mathrm{~N}$ is about 2 degrees smaller than corresponding $\mathrm{Re}-\mathrm{O}-\mathrm{Re}$ angle in $\mathrm{ReO}_{3}$. Such temperature dependence of $\langle\varphi\rangle$ can be related to large anharmonic vibrations of copper in $\mathrm{Cu}_{3} \mathrm{~N}$ at high temperatures, which result in pronounced tilting motion of $\mathrm{NCu}_{6}$ octahedra. Note that this result supports the conclusions of electronic structure studies [72], where it was proposed that it should be easier to tilt the $\mathrm{NCu}_{6}$ units in anti-perovskite-type $\mathrm{Cu}_{3} \mathrm{~N}$ than $\mathrm{ReO}_{6}$ octahedra in perovskite-type $\mathrm{ReO}_{3}$.

\section{Conclusions}

In this study we have demonstrated on the example of anti-perovskite-type $\mathrm{Cu}_{3} \mathrm{~N}$ that EXAFS analysis, coupled with reverse Monte Carlo simulations, is a powerful tool to study not only the local structure of a material, but also to probe its dynamics and correlations in atomic motion. The atomic structure of $\mathrm{Cu}_{3} \mathrm{~N}$ has been simulated using a supercell constructed based on x-ray single-crystal diffraction data [20], whereas the displacements of $\mathrm{Cu}$ and $\mathrm{N}$ atoms due to thermal disorder were optimized using the RMC/EA fitting procedure of the $\mathrm{Cu}$ K-edge EXAFS spectra.

We have found that the lattice dynamics and interatomic interactions in $\mathrm{Cu}_{3} \mathrm{~N}$ bear many resemblances with those in related perovskite-type $\mathrm{ReO}_{3}$. Pronounced anisotropy of $\mathrm{Cu}$ atoms vibrations was detected in $\mathrm{Cu}_{3} \mathrm{~N}$, as it is known for $\mathrm{O}$ atoms in $\mathrm{ReO}_{3}$. Moreover, we have found that strong correlations in the motion of atoms along $-\mathrm{N}-$ $\mathrm{Cu}-\mathrm{N}$ - atomic chains are present in $\mathrm{Cu}_{3} \mathrm{~N}$, as was found in - $\mathrm{Re}-\mathrm{O}-\mathrm{Re}-$ atomic chains in $\mathrm{ReO}_{3}$ [49]. Interatomic interactions in $\mathrm{Cu}_{3} \mathrm{~N}$ have also strong directional dependence, as expected for materials with pronounced covalent bonding. However, the correlations in atomic motion in $\mathrm{Cu}_{3} \mathrm{~N}$ reduces rapidly with the increase of interatomic distance, resulting in less rigid $-\mathrm{N}-\mathrm{Cu}-\mathrm{N}-$ chains. Upon temperature increase the strong anharmonic motion of $\mathrm{Cu}$ atoms in the direction perpendicular to $\mathrm{Cu}-\mathrm{N}$ bond distorts the linear $-\mathrm{N}-\mathrm{Cu}-\mathrm{N}-$ chain, and, as a result, the average value of $\mathrm{N}-\mathrm{Cu}-\mathrm{N}$ angle decreases rapidly, in spite of $\mathrm{Cu}_{3} \mathrm{~N}$ structure remaining always cubic.

At the same time, we have observed a number of similarities between dynamics of atoms in $\mathrm{Cu}_{3} \mathrm{~N}$ and those in metallic copper. Similar arrangements of copper atoms and close $\mathrm{Cu}-\mathrm{Cu}$ distances are present in these two materials, and, importantly, also close absolute amplitudes of $\mathrm{Cu}$ atom vibrations are observed. We have also found that at sufficiently low temperatures the anisotropy of atomic motion in $\mathrm{Cu}_{3} \mathrm{~N}$, imposed by its anti-perovskite type structure, is significantly less pronounced.

A substantial difference, nevertheless, exists between $\mathrm{Cu}_{3} \mathrm{~N}$ and both $\mathrm{ReO}_{3}$ and metallic copper. Most importantly, the pronounced anticorrelated motion of neighboring $\mathrm{Cu}$ atoms occurs along $\mathrm{Cu}-\mathrm{Cu}$ bonds in $\mathrm{Cu}_{3} \mathrm{~N}$ and is consistent with the breathing-type motion of $\mathrm{NCu}_{6}$ octahedra. Such behaviour is not observed neither for $\mathrm{O}$ atoms in $\mathrm{ReO}_{3}$, nor for $\mathrm{Cu}$ atoms in metallic copper.

The obtained detailed information on the temperature dependence of local atomic and dynamic structure of $\mathrm{Cu}_{3} \mathrm{~N}$ provides a background for the development of its theoretical model, based on ab-initio or force-field molecular dynamics methods. We have shown previously [73, 74] that EXAFS data are well suited for such model validation.

\section{Acknowledgements}

This work has been supported by the Latvian National Research Program IMIS2. The EXAFS experiment has been financed from the European Community's Seventh Framework Programme under grant agreement No. 226716 (Project I-20100098 EC). J.T. also gratefully acknowledges support from the National Science Foundation under the DMREF program Grant No. CHE-1534184.

\section{References}

[1] A. S. Bhalla, R. Guo, R. Roy, The perovskite structure - a review of its role in ceramic science and technology, Mater. Res. Innovations 4 (2000) 3-26.

[2] R. E. Cohen, Origin of ferroelectricity in perovskite oxides, Nature 358 (1992) 136-138.

[3] J. G. Bednorz, K. A. Müller, Possible high $\mathrm{T}_{c}$ superconductivity in the Ba-La-Cu-O system, in: Ten Years of Superconductivity: 1980-1990, Springer, 1986, pp. 267-271.

[4] E. L. Nagaev, Colossal-magnetoresistance materials: manganites and conventional ferromagnetic semiconductors, Phys. Rep. 346 (2001) 387-531.

[5] G. A. Samara, The relaxational properties of compositionally disordered $\mathrm{ABO}_{3}$ perovskites, J. Phys.: Condens. Matter 15 (2003) R367-R411.

[6] W. Shen, R. Dittmann, U. Breuer, R. Waser, Improved endurance behavior of resistive switching in $(\mathrm{Ba}, \mathrm{Sr}) \mathrm{TiO}_{3}$ thin films with W top electrode, Appl. Phys. Lett. 93 (2008) 222102.

[7] G. H. Kwei, A. C. Lawson, S. J. L. Billinge, S. W. Cheong, Structures of the ferroelectric phases of barium titanate, J. Phys. Chem. 97 (1993) 2368-2377.

[8] H. Taniguchi, M. Itoh, T. Yagi, Ideal soft mode-type quantum phase transition and phase coexistence at quantum critical point in $\mathrm{O}^{18}$-exchanged $\mathrm{SrTiO}_{3}$, Phys. Rev. Lett. 99 (2007) 017602. 
[9] Y. Girshberg, Y. Yacoby, Off-center displacements and hydrostatic pressure induced phase transition in perovskites, J. Phys.: Condens. Matter 24 (2012) 015901.

[10] E. K. H. Salje, S. A. Hayward, W. T. Lee, Ferroelastic phase transitions: structure and microstructure, Acta Cryst. A 61 (2005) 3-18

[11] I. Levin, V. Krayzman, J. C. Woicik, Local structure in perovskite $(\mathrm{Ba}, \mathrm{Sr}) \mathrm{TiO}_{3}$ : reverse Monte Carlo refinements from multiple measurement techniques, Phys. Rev. B 89 (2014) 024106 .

[12] B. K. Greve, K. L. Martin, P. L. Lee, P. J. Chupas, K. W. Chapman, A. P. Wilkinson, Pronounced negative thermal expansion from a simple structure: cubic $\mathrm{ScF}_{3}$, J. Am. Chem. Soc. 132 (2010) 15496-15498.

[13] C. W. Li, X. Tang, J. A. Munoz, J. B. Keith, S. J. Tracy, D. L. Abernathy, B. Fultz, Structural relationship between negative thermal expansion and quartic anharmonicity of cubic $\mathrm{ScF}_{3}$, Phys. Rev. Lett. 107 (2011) 195504.

[14] J. Purans, P. Fornasini, S. E. Ali, G. Dalba, A. Kuzmin, F. Rocca, X-ray absorption spectroscopy study of local dynamics and thermal expansion in $\mathrm{ReO}_{3}$, Phys. Rev. B 92 (2015) 014302 .

[15] S. Piskunov, P. A. Žguns, D. Bocharov, A. Kuzmin, J. Purans, A. Kalinko, R. A. Evarestov, S. E. Ali, F. Rocca, Interpretation of unexpected behavior of infrared absorption spectra of $\mathrm{ScF}_{3}$ beyond the quasiharmonic approximation, Phys. Rev. B 93 (2016) 214101.

[16] K. Takenaka, H. Takagi, Giant negative thermal expansion in Ge-doped anti-perovskite manganese nitrides, Appl. Phys. Lett. 87 (2005) 1902.

[17] T. He, Q. Huang, A. P. Ramirez, Y. Wang, K. A. Regan, N. Rogado, M. A. Hayward, M. K. Haas, J. S. Slusky, K. Inumara, H. W. Zandbergen, N. P. Ong, R. J. Cava, Superconductivity in the non-oxide perovskite $\mathrm{MgCNi}_{3}$, Nature 411 (2001) 54-56.

[18] K. Kamishima, T. Goto, H. Nakagawa, N. Miura, M. Ohashi, N. Mori, T. Sasaki, T. Kanomata, Giant magnetoresistance in the intermetallic compound $\mathrm{Mn}_{3} \mathrm{GaC}$, Phys. Rev. B 63 (2000) 024426 .

[19] C. M. Caskey, R. M. Richards, D. S. Ginley, A. Zakutayev, Thin film synthesis and properties of copper nitride, a metastable semiconductor, Mater. Horizons 1 (2014) 424-430.

[20] U. Zachwieja, H. Jacobs, Ammonothermalsynthese von kupfernitrid, $\mathrm{Cu}_{3} \mathrm{~N}$, J. Less Common Metals 161 (1990) 175-184.

[21] G. Paniconi, Z. Stoeva, H. Doberstein, R. I. Smith, B. L. Gallagher, D. H. Gregory, Structural chemistry of $\mathrm{Cu}_{3} \mathrm{~N}$ powders obtained by ammonolysis reactions, Solid State Sci. 9 (2007) 907-913.

[22] A. Kuzmin, A. Kalinko, A. Anspoks, J. Timoshenko, R. Kalendarev, Study of copper nitride thin film structure, Latvian J. Phys. Tech. Sci. 53 (2016) 31-37.

[23] M. Asano, K. Umeda, A. Tasaki, $\mathrm{Cu}_{3} \mathrm{~N}$ thin film for a new light recording media, Jap. J. Appl. Phys. 29 (1990) 1985-1986.

[24] T. Maruyama, T. Morishita, Copper nitride and tin nitride thin films for write-once optical recording media, Appl. Phys. Lett. 69 (1996) 890-891.

[25] Z. Ji, Y. Zhang, Y. Yuan, C. Wang, Reactive DC magnetron deposition of copper nitride films for write-once optical recording, Mater. Lett. 60 (2006) 3758-3760.

[26] S. Y. Wang, J. H. Qiu, X. Q. Wang, N. Y. Yuan, J. N. Ding, W. H. Huang, The evolution of $\mathrm{Cu}_{3} \mathrm{~N}$ films irradiated by femtosecond laser pulses, Appl. Surf. Sci. 268 (2013) 387-390.

[27] Y. Zhao, J. Zhao, T. Yang, J. Zhang, J. Yang, X. Li, Enhanced write-once optical storage capacity of $\mathrm{Cu}_{3} \mathrm{~N}$ film by coupling with an $\mathrm{Al}_{2} \mathrm{O}_{3}$ protective layer, Ceram. Int. 42 (2016) 44864490.

[28] J.-M. Park, K. Jin, B. Han, M. J. Kim, J. Jung, J. J. Kim, W.-J. Lee, Atomic layer deposition of copper nitride film and its application to copper seed layer for electrodeposition, Thin Solid Films 556 (2014) 434-439.

[29] L. Maya, Deposition of crystalline binary nitride films of tin, copper, and nickel by reactive sputtering, J. Vacuum Sci. Tech.
A 11 (1993) 604-608

[30] X. Xu, N. Yuan, J. Qiu, J. Ding, Formation of conductive copper lines by femtosecond laser irradiation of copper nitride film on plastic substrates, Mater. Res. Bull. 65 (2015) 68-72.

[31] D. M. Borsa, S. Grachev, C. Presura, D. O. Boerma, Growth and properties of $\mathrm{Cu}_{3} \mathrm{~N}$ films and $\mathrm{Cu}_{3} \mathrm{~N} / \gamma^{\prime}-\mathrm{Fe}_{4} \mathrm{~N}$ bilayers, Appl. Phys. Lett. 80 (2002) 1823-1825.

[32] Y. Fang, J. Persson, C. Zha, J. Willman, C. W. Miller, J. Åkerman, Utility of reactively sputtered $\mathrm{CuN}_{x}$ films in spintronics devices, J. Appl. Phys. 111 (2012) 073912.

[33] H. Wu, W. Chen, Copper nitride nanocubes: size-controlled synthesis and application as cathode catalyst in alkaline fuel cells, J. Am. Chem. Soc. 133 (2011) 15236-15239.

[34] A. Zakutayev, C. M. Caskey, A. N. Fioretti, D. S. Ginley, J. Vidal, V. Stevanovic, E. Tea, S. Lany, Defect tolerant semiconductors for solar energy conversion, J. Phys. Chem. Lett. 5 (2014) 1117-1125.

[35] Q. Lu, X. Zhang, W. Zhu, Y. Zhou, Q. Zhou, L. Liu, X. Wu, Reproducible resistive-switching behavior in copper-nitride thin film prepared by plasma-immersion ion implantation, Phys. Status Solidi A 208 (2011) 874-877.

[36] Q. Zhou, Q. Lu, Y. Zhou, Y. Yang, X. Du, X. Zhang, X. Wu, Influences of preparation methods on bipolar switching properties in copper nitride films, Surf. Coat. Tech. 229 (2013) 135-139.

[37] C. Navio, M. J. Capitan, J. Alvarez, F. Yndurain, R. Miranda, Intrinsic surface band bending in $\mathrm{Cu}_{3} \mathrm{~N}(100)$ ultrathin films, Phys. Rev. B 76 (2007) 085105.

[38] J. Purans, S. Piskunov, D. Bocharov, A. Kalinko, A. Kuzmin, S. E. Ali, F. Rocca, Local structure of perovskites $\mathrm{ReO}_{3}$ and $\mathrm{ScF}_{3}$ with negative thermal expansion: interpretation beyond the quasiharmonic approximation, J. Phys.: Conf. Ser. 712 (2016) 012013.

[39] U. Hahn, W. Weber, Electronic structure and chemical-bonding mechanism of $\mathrm{Cu}_{3} \mathrm{~N}, \mathrm{Cu}_{3} \mathrm{NPd}$, and related $\mathrm{Cu}(\mathrm{I})$ compounds, Phys. Rev. B 53 (1996) 12684-12693.

[40] W. Yu, J. Zhao, C. Jin, Simultaneous softening of $\mathrm{Cu}_{3} \mathrm{~N}$ phonon modes along the T2 line under pressure: a first-principles calculation, Phys. Rev. B 72 (2005) 214116.

[41] M. G. Moreno-Armenta, A. Martinez-Ruiz, N. Takeuchi, Ab initio total energy calculations of copper nitride: the effect of lattice parameters and $\mathrm{Cu}$ content in the electronic properties, Solid State Sci. 6 (2004) 9-14.

[42] T. Nosaka, M. Yoshitake, A. Okamoto, S. Ogawa, Y. Nakayama, Copper nitride thin films prepared by reactive radio-frequency magnetron sputtering, Thin Solid Films 348 (1999) 8-13.

[43] D. E. Sayers, E. A. Stern, F. W. Lytle, New technique for investigating noncrystalline structures: Fourier analysis of the extended X-ray-absorption fine structure, Phys. Rev. Lett. 27 (1971) 1204.

[44] P. A. Lee, P. H. Citrin, P. Eisenberger, B. M. Kincaid, Extended X-ray absorption fine structure - its strengths and limitations as a structural tool, Rev. Mod. Phys. 53 (1981) 769.

[45] J. J. Rehr, R. C. Albers, Theoretical approaches to X-ray absorption fine structure, Rev. Mod. Phys. 72 (2000) 621-654.

[46] P. Fornasini, R. Grisenti, On EXAFS Debye-Waller factor and recent advances, J. Synchrotron Rad. 22 (2015) 1242-1257.

[47] A. Di Cicco, A. Trapananti, S. Faggioni, A. Filipponi, Is there icosahedral ordering in liquid and undercooled metals?, Phys. Rev. Lett. 91 (2003) 135505.

[48] J. Timoshenko, A. Kuzmin, J. Purans, EXAFS study of hydrogen intercalation into $\mathrm{ReO}_{3}$ using the evolutionary algorithm, J. Phys.: Condens. Matter 26 (2014) 055401.

[49] J. Timoshenko, A. Kuzmin, J. Purans, Disappearance of correlations in the atom motion upon hydrogen intercalation into $\mathrm{ReO}_{3}$ lattice, J. Phys.: Conf. Ser. 712 (2016) 012003.

[50] R. L. McGreevy, L. Pusztai, Reverse Monte Carlo simulation: a new technique for the determination of disordered structures, Mol. Simul. 1 (1988) 359-367.

[51] J. Timoshenko, A. Kuzmin, J. Purans, Reverse Monte Carlo modeling of thermal disorder in crystalline materials from EXAFS spectra, Comp. Phys. Commun. 183 (2012) 1237-1245. 
[52] J. Timoshenko, A. Kuzmin, J. Purans, An efficient implementation of the reverse Monte Carlo method for EXAFS analysis in crystalline materials, J. Phys.: Conf. Ser. 430 (2013) 012012.

[53] A. Anspoks, J. Timoshenko, J. Purans, F. Rocca, V. Trepakov, A. Dejneka, I. M, Local dynamics and phase transition in quantum paraelectric $\mathrm{SrTiO}_{3}$ studied by Ti K-edge X-ray absorption spectroscopy, J. Phys.: Conf. Ser. 712 (2016) 012101.

54] I. Jonane, J. Timoshenko, A. Kuzmin, Atomistic simulations of the Fe K-edge EXAFS in $\mathrm{FeF}_{3}$ using molecular dynamics and reverse Monte Carlo methods, Phys. Scr. 91 (10) (2016) 104001.

[55] J. Timoshenko, A. Anspoks, A. Kalinko, A. Kuzmin, Local structure of copper nitride revealed by EXAFS spectroscopy and a reverse Monte Carlo/evolutionary algorithm approach, Phys. Scr. 91 (2016) 054003.

[56] K. Rickers, W. Drube, H. Schulte-Schrepping, E. Welter, U. Brüggmann, M. Herrmann, J. Heuer, H. Schulz-Ritter, New XAFS facility for in-situ measurements at beamline $\mathrm{C}$ at $\mathrm{HA}$ SYLAB, AIP Conf. Proc. 882 (2007) 905-907.

57] V. L. Aksenov, M. V. Koval'chuk, A. Y. Kuz'min, Y. Purans, S. I. Tyutyunnikov, Development of methods of EXAFS spectroscopy on synchrotron radiation beams: review, Cryst. Rep. 51 (2006) 908-935.

[58] A. Kuzmin, EDA: EXAFS data analysis software package, Physica B 208-209 (1995) 175-176.

[59] B. Ravel, M. Newville, ATHENA, ARTEMIS, HEPHAESTUS: data analysis for X-ray absorption spectroscopy using IFEFFIT, J. Synchrotron Rad. 12 (2005) 537-541.

60] S. J. Gurman, R. L. McGreevy, Reverse Monte Carlo simulation for the analysis of EXAFS data, J. Phys.: Condens. Matter 2 (1990) 9463.

[61] R. L. McGreevy, P. Zetterström, Reverse Monte Carlo modelling of network glasses: useful or useless?, J. Non-Cryst. Solids 293-295 (2001) 297-303.

[62] J. Timoshenko, A. Anspoks, A. Kalinko, A. Kuzmin, Local structure of cobalt tungstate revealed by EXAFS spectroscopy and reverse Monte Carlo/evolutionary algorithm simulations, Z. Phys. Chem. 230 (2016) 551.

[63] M. E. Straumanis, L. S. Yu, Lattice parameters, densities, expansion coefficients and perfection of structure of $\mathrm{Cu}$ and of Cu-In $\alpha$ phase, Acta Crystallogr. A 25 (1969) 676-682.

[64] A. L. Ankudinov, B. Ravel, J. J. Rehr, S. D. Conradson, Realspace multiple-scattering calculation and interpretation of $\mathrm{X}$ ray-absorption near-edge structure, Phys. Rev. B 58 (1998) $7565-7576$.

[65] P. Fornasini, Study of lattice dynamics via extended X-ray absorption fine structure, J. Phys.: Condensed Matter 13 (2001) $7859-7872$.

[66] E. Sevillano, H. Meuth, J. J. Rehr, Extended X-ray absorption fine structure Debye-Waller factors. I. Monatomic crystals, Phys. Rev. B 20 (1979) 4908.

[67] A. Kuzmin, J. Purans, M. Benfatto, C. R. Natoli, X-rayabsorption study of rhenium $\mathrm{L}_{3}$ and $\mathrm{L}_{1}$ edges in $\mathrm{ReO}_{3}$ : Multiple-scattering approach, Phys. Rev. B 47 (1993) 24802486 .

[68] A. Kuzmin, J. Purans, A new fast spherical approximation for calculation of multiple-scattering contributions in X-ray absorption fine structure and its application to $\mathrm{ReO}_{3}, \mathrm{NaWO}_{3}$ and $\mathrm{MoO}_{3}$, J. Phys.: Condens. Matter 5 (1993) 267-282.

[69] S. a Beccara, G. Dalba, P. Fornasini, R. Grisenti, F. Pederiva, A. Sanson, D. Diop, F. Rocca, Local thermal expansion in copper: extended X-ray-absorption fine-structure measurements and path-integral Monte Carlo calculations, Phys. Rev. B 68 (2003) 140301.

[70] P. Fornasini, G. Dalba, R. Grisenti, J. Purans, A. Sanson, M. Vaccari, F. Rocca, EXAFS studies of lattice dynamics and thermal expansion, Phys. Status Solidi C 1 (2004) 3085-3088.

[71] N. Singh, P. K. Sharma, Debye-Waller factors of cubic metals, Phys. Rev. B 3 (1971) 1141.

[72] G. V. Vajenine, C. Hoch, R. E. Dinnebier, A. Senyshyn, R. Niewa, A temperature-dependent structural study of anti$\mathrm{ReO}_{3}$-type $\mathrm{Na}_{3} \mathrm{~N}$ : to distort or not to distort?, Z. Anorg. Allg.
Chem. 636 (2010) 94-99.

[73] J. Timoshenko, A. Anspoks, A. Kalinko, A. Kuzmin, Temperature dependence of the local structure and lattice dynamics of wurtzite-type ZnO, Acta Mater. 79 (2014) 194-202.

74] A. Kuzmin, A. Anspoks, A. Kalinko, J. Timoshenko, The use of X-ray absorption spectra for validation of classical force-field models, Z. Phys. Chem. 230 (2016) 537-549. 